\title{
EVROPSKI JEZIKI: INSTRUMENTI IN SIMBOLI
}

Ključne besede: evropski jeziki, vloga latinščine, lingua franca, nacionalni jeziki, ogroženost jezika, jezikovno načrtovanje

\section{Izhodišče}

Jezik kot poseben sistem znakov je seveda najprej orodje za sporazumevanje, za učinkovito prenašanje sporočil, in morda je bila prav to njegova prvotna funkcija. Ni pa nujno: mogoče je, da je bil jezik najprej sredstvo za ustvarjanje in ohranjanje odnosov znotraj skupine, kar je med drugim tudi danes; obenem je jezik sredstvo za izražanje še drugačnih, nadpragmatičnih vsebin, kot npr. v umetnostnih besedilih. Prav spričo raznolikosti vlog, ki jih jezik kot univerzalno sredstvo sporazumevanja opravlja, je instrument za prenašanje sporočil, obenem pa vselej tudi simbol raznovrstnih pripadnosti, npr. določenemu narodu ali kulturni skupini, in zato pomemben element posameznikove identitete, prek katerega se prenaša zgodovinska dediščina njegovih govorcev in njihovih kultur, ki se skoz jezik ohranja na edinstven način v svoji živosti in spremenljivosti. S posameznimi jeziki povezane kulture imajo časovne in prostorske koordinate, in ko se sprašujemo o identiteti določenega prostora, ne moremo mimo njegovih jezikovnih značilnosti.

V tem prispevku bomo skušali orisati nekaj temeljnih potez današnje Evrope s stališča njenih jezikov, njihove vloge in rabe. Seveda je tema tako kompleksna in neizčrpna, da bo mogoče zgolj nakazati nekaj iztočnic, ki kličejo po poglobljeni razpravi. 


\section{II »(Ne)evropskost« evropskih jezikov}

V izhodišču je treba opozoriti na potrebo po ločevanju med sintagmama »evropski jeziki« in »jeziki v Evropi«; koncept, na katerega se nanašajo »evropski jeziki« in s katerim se bomo ukvarjali v tem prispevku, je ožji od pojma »jeziki v Evropi«, saj slednji vključuje tudi jezike, ki se govorijo v Evropi, a so bili sem prineseni od drugod po ustalitvi evropske jezikovne podobe. To so predvsem jeziki, s katerimi so evropski jeziki prihajali in v stik na evropskem ali na zunajevropskih ozemljih; pogosto so to jeziki različnih skupnosti priseljencev, ki so se naselile v Evropi, oz. priseljenski jeziki (npr. arabščina, japonščina, kitajščina, svahilščina itd.). Ti jeziki so na evropske jezike na različne načine vplivali, kot je razvidno predvsem iz besedja posameznih evropskih jezikov, ki pogosto priča o prevzemanju besedišča skupaj s sprejemanjem elementov zunajjezikovne realnosti, na katero se takšno besedje nanaša (tako je npr. ital. zucchero »sladkor« arabskega, angl. tea »čaj« kitajskega in slov. tajkun, prevzeto verjetno prek angleščine, japonskega izvora). Nadalje je na evropske jezike predvsem skoz svetopisemsko leksiko pomembno vplivala hebrejščina.

Seveda v zgodovinskem pogledu tudi današnji evropski jeziki v resnici niso »evropski«, saj niso avtohtoni, temveč so jih sèm z migracijami prinesli njihovi govorci v različnih prazgodovinskih in zgodovinskih obdobjih in tu so »novi« evropski jeziki vsrkali dediščino jezikov, ki so se na evropskem ozemlju govorili ob prihodu priseljencev. Toda po preseljevanju narodov v zgodnjem srednjem veku se je pritok novih etnično-jezikovnih skupin, ki bi si prisvojile dele evropskega ozemlja, ustavil, s tem pa se je končalo tudi vstopanje novih jezikov, ki bi podobo Evrope $\mathrm{v}$ tipološkem pogledu bistveno spremenili. V naslednjih stoletjih se je nadaljevalo izumiranje jezikov (npr. gotščina, vandalščina, langobardščina, dalmatščina) in nastajanje novih (romanski, germanski, slovanski jeziki), toda pomembnega pritoka »zunanjih« jezikov ni več bilo. Pač pa so se evropski jeziki pozneje, s kolonialnim osvajanjem sveta širili na druge celine in njihovo jezikovno podobo korenito spreminjali ter avtohtone jezike pogosto zatirali do uničenja. Rezultat tega procesa je, da se evropski jeziki danes govorijo tudi na vseh ostalih celinah, kjer so pogosto večinski jeziki, kot v Avstraliji in v obeh Amerikah, v odnosu do evropskih jezikov, ki jih nadaljujejo, pa v 
številnih primerih predstavljajo nove različice (takšna je npr. ameriška, kanadska, avstralska, indijska angleščina v razmerju do britanske angleščine ali brazilska portugalščina $\mathrm{v}$ razmerju do iberske portugalščine). Ti jeziki bi se utegnili v prihodnosti oblikovati v povsem nove jezike, ki z britansko angleščino ne bi bili več avtomatično medsebojno razumljivi. Toda da bi se to zgodilo, bi moral razvoj v smeri divergence potekati dovolj dolgo, pa tudi izravnalnih učinkov, kot jih bo verjetno imela globalizacija, ne bi smelo biti, zato takšen scenarij ni najverjetnejši. Nadalje so se iz stika med evropskimi in avtohtononi jeziki razvili številni pidžinski in kreolski jeziki, značilni npr. za karibsko območje, poleg tega se evropski jeziki, kot se uporabljajo zunaj Evrope, pogosto oplajajo iz stika z domačimi jeziki (npr. angleščina v Indiji, francoščina v zahodni Afriki itd.), rezultat česar so prav tako nove različice evropskih jezikov.

Evropski jeziki spadajo sicer v različne jezikovne skupine: daleč najmočneje zastopana je indoevropska, tu so pa še ugrofinski jeziki in baskovščina ter na obrobju Evrope malteščina kot edini evropski semitski jezik, altajski jeziki (turščina, kalmiščina) in kavkaški jeziki (npr. gruzinščina, čečenščina), kolikor seveda območje Kavkaza v geografskem pogledu prištevamo k Evropi; poleg teh sta $\mathrm{z}$ Evropo tesno povezana dva neteritorialna jezika, se pravi jezika, katerih govorci nimajo svojega specifičnega etničnega ozemlja: jidiš in romski jezik. Oba sta indoevropska jezika: jidiš je germanskega, ${ }^{1}$ romščina pa indoarijskega izvora. Jidiš, ki se je razvil pred približno tisoč leti v Porenju in Podonavju, se danes v Evropi skoraj ne govori več, pač pa ima nekaj milijonov govorcev, razkropljenih po vsem svetu; romščina se govori predvsem v Evropi, in sicer v večini evropskih držav.

Toda kljub zastopanosti številnih jezikovnih skupin je Evropa jezikovno razmeroma enovita, če jo primerjamo z nekaterimi drugimi deli sveta, npr. $\mathrm{z}$ osrednjo Afriko ali s tihomorskim območjem, za katera sta značilna izjemna jezikovna raznolikost (prim. Nettle/Romaine, 2000, 27, 33) in obenem nesta-

1 Za jidiš sta pomembni dve indoevropski komponenti (germanska in slovanska) in dve semitski komponenti (hebrejska in aramejska), a jezikoslovci se v glavnem strinjajo, da gre tipološko za germanski jezik. Poleg jidiša, ki je jezik Aškenazov, so judje na različnih koncih Evrope in $\mathrm{v}$ različnih obdobjih uporabljali, tako $\mathrm{v}$ pisavi kot $\mathrm{v}$ govoru, variante hebrejščine. $\mathrm{V}$ času med obema vojnama je bil npr. na Poljskem razvit sistem šol s hebrejščino kot učnim jezikom (prim. Glinert, 1998, 228). 
bilnost, saj je izumiranje jezikov prav tam največje. Ti jeziki so v primerjavi z evropskimi pogosto slabo dokumentirani, saj mnogokdaj pripadajo izključno ustnim tradicijam. Kar je za Evropo v primerjavi z ostalimi celinami v jezikovnem pogledu svojsko, je ravno sorazmerna solidna izpričanost njenih jezikov - čeprav nikakor ne vseh - ter homogenost in razvojna kontinuiteta. Evropski jeziki so se v vseh zgodovinskih obdobjih spreminjali - pomislimo samo na to, kako neberljiva so danes za nespecialista npr. angleška, francoska ali slovenska besedila izpred nekaj stoletij. Do kompleksnega jezikovnega spreminjanja je prihajalo tako zaradi notranjih dejavnikov oz. zaradi naravnega jezikovnega razvoja kot zaradi zunanjih dejavnikov, kot so stiki z drugimi jeziki in ukrepi jezikovnega načrtovanja, ki je pogosto, kot bomo videli pozneje, obenem tudi politično načrtovanje - vendar ne glede na to je tipološka slika evropskih jezikov več kot tisočletje precej stalna.

\section{Dediščina latinščine}

Toda onkraj tipološke stabilnosti lahko v evropski zgodovini zadnjih dveh tisočletij prepoznamo jezik, ki je po svoji dolgoročni pomembnosti izrazito drugačen od vseh ostalih: latinščina. Njegova zgodovinska teža daleč presega vpliv, ki ga je ta jezik imel - in ga še zmeraj ima - na druge jezike, in v resnici pomeni eno izmed temeljnih značilnosti, po katerih se evropska civilizacija konstituira. Če ima slednja zares trdne skupne lastnosti, je med njimi zagotovo latinščina kot skupni kulturni kod. Nedvomno je ogromna tudi dediščina grške cilivilizacije - ki so jo Rimljani občudovali in se trudili, da bi Grke dohiteli - in grškega jezika, toda v veliki meri je grščina vplivala na evropske jezike prek posredništva latinščine, ki je iz grščine prevzela med drugim obilo leksikalnega gradiva na področju medicine, glasbe, filozofije, kulinarike itd. Tako je latinščina brez dvoma jezik, ki je dal Evropi največji pečat, saj je njegov vpliv najrazsežnejši in najintenzivnejši v času in prostoru. Različne politične tvorbe, ki so skoz stoletja ta jezik uporabljale kot uradni jezik ali kot enega izmed uradnih jezikov, so propadle, druge so latinščino zamenjale $\mathrm{z}$ modernejšimi jeziki, celo latinščina sama se je preobrazila v romanske jezike - ki se pomenljivo imenujejo tudi »novolatinski« -, a ne glede na vse okoliščine je jezik obstal in se v evropski 
zgodovini izkazal za daleč najvplivnejšega. Morda paradoksalno, a vendar: verjetno je razlog za nepretrgano pomembnost latinščine deloma tudi $\mathrm{v}$ tem, da gre za jezik, ki je razvojno v glavnem zaustavljen, še zdaleč pa ne mrtev, kot sicer lahko trdimo o mnogih drugih evropskih jezikih, vključno npr. z latinščini sodobnimi jeziki, kot so etruščina, oskijščina, venetščina itd. Latinščina se v različnih okoljih še vedno uporablja - čeprav večinoma ne kot popolni, temveč kot terminološki kod (npr. v pravu, medicini, botaniki itd.), ${ }^{2}$ in sicer v glavnem pri pisnem sporočanju; latinščina je tudi jezik katoliške cerkve in nekaterih drugih institucij. Toda nima več funkcije materinščine oz. prvega jezika, saj se ne usvaja naravno; morda ravno zato lahko v fiksnosti slovnične kodificiranosti še vedno ostaja referenčna točka pri terminološkem sporočanju med strokovnjaki, ki bi se med seboj drugače težje sporazumeli, ali pri kovanju najsodobnejšega izrazja v različnih jezikih, kot pričata med drugim neologizma s konca 20. stoletja, internet in intranet. ${ }^{3}$ Navsezadnje je latinščina jezik, ki se več kot dva tisoč let poučuje $\mathrm{v}$ šolah širom Evrope in v zadnjih stoletjih tudi na vseh ostalih celinah. Vse prej kot o njeni neaktualnosti pričajo tudi latinski prevodi različnih literarnih del, tudi mladinskih, kot so stripi o Asteriksu pa zgodbe o Maxu in Moritzu in o Harryju Potterju.

Prisotnost latinščine je danes raznolika in večplastna: najprej neposredna, kolikor se latinščina še zmeraj uporablja za znanstveno-strokovno komunikacijo pa tudi za druge vrste sporočanja, npr. literarno; obenem predstavljajo latinski elementi temeljni sestavni del besedja zelo različnih jezikov, ki so se skoz stoletja iz nje napajali (prim. Ostler, 2007, 294-296). $\mathrm{Na}$ poseben način se latinščina nadaljuje tudi v romanskih jezikih, prek katerih dalje vpliva na druge jezike; tako je npr. angleščina najbolj romaniziran germanski jezik, ki je iz latinščine $v$ različnih obdobjih črpal neposredno, latinsko gradivo pa je prevzemal tudi prek romanskih jezikov, izrazito prek normanske francoščine, torej jezika Normanov, ki so bili romanizi-

2 Iz evropske zgodovine različnih obdobij so znane posebne terminološke rabe latinščine kot jezika, ki v nasprotju z ljudskimi oz. nacionalnimi jeziki ni bil splošno razumljiv in je bil zato prikladen za izražanje vsebin, povezanih z boleznimi, anatomijo, spolnostjo itd., ki bi sicer lahko sprožile zadrego ali pa ranljive ogrozile (gl. Waquet, 2001, 243 et seqq.).

3 Leksema intranet in internet sestojita iz latinskih predpon intra- in inter- ter germanskega samostalnika net (»mreža«). 
rano germansko ljudstvo. Iz latinščine prevzeto gradivo najdemo v vseh evropskih jezikih, od valežanščine na zahodnem evropskem obrobju in islandščine na skrajnem severozahodu, do ruščine na vzhodu in od skandinavskih jezikov na severu do malteščine na jugu. Iz latinščine oz. od njenih govorcev Rimljanov imamo pisavo, na izvor katere nas spominja že samo ime, latinica, ki je nastala iz različice grške pisave, kakršna se je razvila na Italskem polotoku. Prav tako je latinska tradicija dokončno utrdila smer pisanja od leve proti desni. ${ }^{4}$

\section{Evropska lingua franca: Zakaj latinščina?... Zakaj angleščina?}

Zakaj je evropska zgodovinska lingua franca ravno latinščina? Navsezadnje je bila ta najprej le eden izmed italskih jezikov, ki se je uporabljal na manjšem območju kot mnogi drugi, in sicer v Rimu in njegovi okolici. Toda pozneje je z vojaško-političnim vzponom Rimljanov in s širitvijo imperija latinščina postala najvažnejši in najprestižnejši evropski jezik, pred katerim so klonili številni jeziki na osvojenih ozemljih blizu in daleč središča rimske moči, denimo jezik Etruščanov, ki je imel od latinščine starejšo pisno tradicijo ${ }^{5}$ in je bil sporazumevalno sredstvo visoke kulture, pa tudi npr. galščina in iberščina. Učinek prodiranja latinščine kot jezika evropske politične in nenazadnje tudi gospodarske velesile je bil za številne jezike v Evropi in zunaj nje uničujoč; po nekaterih izračunih se je v petih stoletjih, od 100 pr. n. š. do 400 n. š., število jezikov na območjih, ki so prišla pod rimsko upravo, zmanjšalo za štiri petine (Ostler, 2007, 14). Toda prodor latinščine se je nadaljeval na še silovitejši način, ko je s krstom cesarja Konstantina

4 Poleg pisave smo od Rimljanov seveda dobili tudi serijo številk.

5 Prvi dokumenti v latinščini so zapisi na vinskih posodah in naj bi izvirali iz obdobja 600620 pr. n. š., prva povezana besedila pa so iz 3. stoletja pr. n. š. (Baldi, 2002, 28); zapisi v etruščini so vsaj nekaj desetletij starejši, etruščanska civilizacija pa je bila bogato razvita nekaj stoletij pred latinsko. Tako so Rimljani Etruščane posnemali v marsičem; od Etruščanov so npr. prevzeli sistem trodelnega poimenovanja članov skupnosti (praenomen, nomen oz. gentilicium, cognomen); iz etruščine izvirajo številne latinske besede, ki pričajo o tem, da so se Rimljani od Etruščanov veliko naučili npr. na področju kulinarike, zabave in urbanega življenja. 
leta 337 krščanstvo postalo religija rimskega imperija, s širitvijo krščanstva znotraj imperija - ki je bil razmeroma prehoden spričo dobre mreže cest, za gradnjo katerih so Rimljani prav posebno skrbeli - in zunaj njega pa sta se vpliv in pomembnost latinščine še povečevala. In čeprav je cesarstvo propadlo, nove politične okoliščine latinščine v resnici niso ogrozile, saj se je njena vloga uradnega jezika nadaljevala $v$ mnogih poznejših državnih formacijah. Pravzaprav je bil za latinščino kot funkcijsko polno razvit jezik najusodnejši udarec nastanek romanskih jezikov kot nadaljevalcev najbolj žive, predvsem govorjene plasti latinščine, tj. vulgarne latinščine.

Z nekaj domišljije lahko ugotovimo, da so razlogi, zaradi katerih je latinščina postala evropska lingua franca, do neke mere podobni razlogom, ki botrujejo statusu angleščine kot sodobnega globalnega jezika. Najprej naj omenimo, da je angleščina v vzponu že nekaj stoletij; tako je bil npr. David Hume že sredi 18. stoletja prepričan, da ima angleščina izjemno prihodnost, stoletje pozneje pa je Jakob Grimm ugotavljal, da je angleščina svetovni jezik, ki se bo v prihodnosti še nadalje krepil (Crystal, 1998, 74). Pri njeni ekspanziji so imeli odločilno vlogo kolonializem nasploh, predvsem pa širitev v Severno Ameriko in pozneje v Avstralijo ter tamkajšnja naselitev angleško govorečega prebivalstva, kar je privedlo do izrazite okrepitve statusa angleščine na svetovni ravni. Kot meni David Crystal, je uspešnost angleščine mogoče razlagati s tem, da je bil ta jezik večkrat ob pravem času na pravem mestu: v 17. in 18. stoletju je bila angleščina jezik Velike Britanije, ki je bila takrat najmočnejša kolonialna država, nato je bila v 18. in 19. stoletju jezik Velike Britanije kot vodilne sile industrijske revolucije, na koncu 19. in na začetku 20. stoletja pa jezik Združenih držav Amerike kot glavne gospodarske sile (ibid., 1998, 110). Posledica vsega navedenega je med drugim to, da je veliko znanja postalo dostopnega ravno $\mathrm{v}$ angleščini (ibid., 1998, 71-73), s čimer se je začel njen vzpon na področju znanstvenega in strokovnega komuniciranja. Število govorcev angleščine se je vzpenjalo in za vse več ljudi, ki so angleščino usvojili, ta ni bila jezik osvajalcev, temveč »nevtralni« sporazumevalni jezik. Podobno kot prej z latinščino je zdaj tudi $\mathrm{z}$ angleščino tako, da za jezikom stojijo pomembne politične formacije in ogromen gospodarski kapital. Položaj latinščine nekoč in angleščine danes jasno kažeta, da je vloga posameznih jezikov pogojena izrazito zunanje; nič ni namreč imanentno jezikovnega, zaradi česar 
bi bil dani jezik bolj kot kakšen drug prikladen za to, da prevzame denimo vlogo linguae francae.

Na tem mestu bi se glede na povedano lahko vprašali, zakaj je vloga globalnega jezika v sodobnem svetu pripadla ravno angleščini, ne pa francoščini, ki je v Evropi dolgo prevladovala kot lingua franca in v tej vlogi v veliki meri nadomestila latinščino. Francoščina je bila jezik diplomacije, dvorov, kulture. Širila se je po vsej Evropi; npr. že sredi 11. stoletja je kot normanska francoščina z zmago Viljema Osvajalca pri Hastingsu začela svoj zmagovit prodor na Britansko otočje in tam na številnih področjih rabe stopila na mesto domače angleščine in postala jezik kulture; višji sloji so bili pogosto dvojezični, nižji pa so govorili angleško. ${ }^{6}$ Pozneje, s prodiranjem francoske kolonialne moči, se je francoščina širila tudi na druge celine. Toda drugače od angleščine francoščina zunaj matične države ni nikoli postala jezik kakšne velike sile, temveč le jezik kolonij, večinoma $\mathrm{z}$ razmeroma maloštevilnimi prebivalci, ki so svoje jezike vsaj deloma ohranili (prim. Calvet, 1999, 246-251). Vpliv francoščine je bil torej po eni strani - zaradi kolonialne širitve - političen, po drugi pa kulturen, ne pa izrazito gospodarski. Toda kot jezik kulture je imela francoščina razmeroma malo govorcev, saj v tej vlogi nikoli ni bila jezik množic; zato se je njen pomen v Evropi z vznikom nacionalnih jezikov, drugače kot vpliv angleščine, ki je imela še vse kaj drugega kot zgolj kulturni potencial, od srede 19. stoletja dalje vztrajno zmanjševal.

\section{Lingua franca in nacionalni jeziki}

Prebujanje nacionalne zavesti in krepitev nacionalnih jezikov se je zares razmahnilo šele $\mathrm{v}$ obdobju romantike, toda $\mathrm{v}$ resnici pomeni krepitev nacionalnih jezikov v tej dobi nadaljevanje procesa, ki je v Evropi trajal že dolgo. Ko je Dante na začetku 14. stoletja v enciklopedično zastavljenem in

6 O jezikovnih navadah $\mathrm{v}$ tej razslojeni družbi na sociolingvistično pomenljiv način pričajo tudi imena živali na eni strani in imena jedi iz njihovega mesa na drugi strani; domače prebivalstvo se je ukvarjalo večinoma z rejo, zato so imena živali angleška (calf, cow, deer, sheep, swine), normanski višji sloji pa so imeli opravka predvsem s hrano, pripravljeno iz mesa teh živali, zaradi česar imena jedi izvirajo iz francoščine (veal, beef, venison, mutton, pork). 
v italijanščini napisanem delu Convivio, vulgarni jezik kot sporazumevalno sredstvo vseh postavil nad latinščino in ga primerjal s kruhom, ki bo nasitil množice, in s soncem, ki vzhaja hkrati z zatonom latinščine, je razmišljal $\mathrm{v}$ isti smeri uveljavljanja »novega« jezika, ki je bil v odnosu do močnejšega in prestižnejšega jezika v podrejenem položaju, le da se je Dante boril proti latinščini - ki jo je sicer za potrebe strokovnega komuniciranja večkrat uporabil, tudi ko je razpravljal o jeziku, kot priča spis De vulgari eloquentia -, medtem ko so bili v 19. stoletju nasprotniki novih nacionalnih jezikov drugi dominantni jeziki, npr. nemščina, če vzamemo slovensko situacijo. Z uveljavitvijo koncepta naroda, nacionalne države in nacionalnega jezika se je začel proces korenitega prevrednotenja vloge, ki jo imajo jeziki v življenju skupnosti in posameznika. Medtem ko je lingua franca kot jezik, ki se ga naučimo zaradi komunikacijskih potreb, za govorce predvsem instrument, je pri nacionalnem jeziku vselej pomembna tudi vloga simbola. Znanje linguae francae kot splošno sporazumevalnega jezika je uporabno iz praktičnih razlogov, saj je zmožnost najširšega in učinkovitega mednarodnega komuniciranja seveda prikladna in potrebna, toda zgolj za komuniciranje navzven, medtem ko komunikacija znotraj posameznih nacionalnih oz. jezikovnih skupnosti poteka s pomočjo nacionalnih in drugih jezikov, ki niso angleščina, razen seveda za tiste, za katere je ta jezik materinščina, kot takšna pa se na vseh jezikovnih ravninah večinoma zelo razlikuje od angleščine kot najširše uporabljane linguae francae.

Tako v današnji Evropi lahko opažamo dve, vsaj navidezno nasprotujoči si težnji: prvič, stremljenje k splošnemu sporazumevalnemu jeziku, in drugič, povečano pozornost do nedržavnih, manjšinskih in manj rabljenih jezikov, ${ }^{7}$ na kar kaže med drugim to, da je bila leta 1992 pri Svetu Evrope v

7 Ob strani puščava vprašanje o tem, kaj je jezik in kaj narečje, in vseskoz uporabljava izključno termin jezik. Splošno znana je krilatica, da je jezik narečje, ki ima za seboj vojsko in mornarico. Aforizem sicer dobro nakazuje, da je razlikovanje med jeziki in narečji stvar zunajjezikovnih dejavnikov, ni pa seveda točna; slovenščina npr. je bila jezik že davno, preden je postala državni jezik. Dejstvo je, da so se številni evropski jeziki razvili iz lokalnih jezikovnih različic oz. narečij bodisi iz političih razlogov kot npr. v Franciji - kjer je spričo centralizacijskih teženj oblasti jezik območja Île-de-France postal osnova za francoščino - ali pa iz kombinacije pretežno kulturno- in književnozgodovinskih razlogov kot npr. v Italiji, kjer je prevladala toskanščina, natančneje florentinščina, v kateri so konec 13 . in v začetku 14. stoletja nastala besedila izjemne literarne vrednosti. 
Strasbourgu podpisana Evropska listina o regionalnih ali manjšinskih jezikih, ki jo je pozneje ratificirala tudi Slovenija. ${ }^{8}$ Splošno sporazumevalni jezik je danes predvsem angleščina, in njena prevlada ima nedvomno negativne posledice za zastopanost drugih jezikov, ki bi vlogo evropske linguae francae prav tako lahko opravljali, kot so npr. nemščina, španščina in francoščina. Toda na globalni ravni je angleščina kot splošno sporazumevalni jezik brez konkurence; kombinacija različnih dejavnikov, kot so število govorcev angleščine, nato gospodarska, politična in kulturna moč angleško govorečih dežel ter količina besedil najrazličnejših vrst in zvrsti, ki so na voljo $\mathrm{v}$ angleščini, je takšna, da si zaenkrat realno ni mogoče predstavljati okoliščin, v katerih bi ta jezik svojo premoč izgubil. ${ }^{9}$ Preveč tvegano je namreč, če danes ne znamo angleško, in nezmožnost vsaj receptivne rabe tega jezika bi lahko predvsem mlade generacije močno deprivilegirala tako v službi kot zunaj nje. Nadmoč angleščine pa obstoja drugih jezikov ne ogroža nujno, vsaj ne v današnji Evropi,${ }^{10}$ čeprav v preteklosti ni bilo zmeraj tako. Na Britanskem otočju so keltski jeziki (kumbrijščina, irščina, gelščina, manščina, valežanščina in kornijščina) zatonili prav zaradi prevlade angleščine. Npr. valežanščina, ki je imela bogato književno tradicijo in ki ima danes med keltskimi jeziki najtrdnejši položaj, se je v osrednjem in zahodnem Walesu dolgo obdržala; še na začetku 20. stoletja je valežansko govorila polovica prebivalstva, od katerega jih je bilo $15 \%$ celo brez znanja angleščine; v naslednjih sedemdesetih letih pa je prišlo do skokovitega upada: leta 1971 je namreč valežansko govorila le še petina prebivalcev (Nettle/Romaine, 2000, 135-136). Valežanščina pa tudi drugi keltski jeziki na Britanskem otočju so se $\mathrm{v}$ zadnjih desetletjih začeli spet prebujati, a proces oživljanja jezikov je vselej dolgotrajen in zamuden, celo $\mathrm{v}$ okoljih, kjer ima politično in gospodarsko podporo kot npr. na Irskem (Crowley, 2005, 164), saj je odvisen od številnih dejavnikov, kot so število govorcev, okoliščine rabe, medgeneracij-

8 Eno redkih v slovenščini dostopnih neposrednih pričevanj o jezikovnih manjšinah v Evropi ponuja Brezigar (1999).

9 Za oceno moči posameznega jezika je Augusto Carli predlagal upoštevanje naslednjih dejavnikov: vloga v mednarodni komunikaciji, število govorcev, ekonomska moč skupnosti govorcev, vloga pri znanstveni komunikaciji, vloga $\mathrm{v}$ komunikaciji množičnih medijev (prim. Carli, 2000).

10 Drugačno je stanje na mnogih drugih koncih sveta, kjer angleščina tekmuje z jeziki - pogosto takšnimi brez pisne tradicije -, ki se zaradi njene prevlade funkcijsko ožijo (Nettle/Romaine, 2000, 55 in sl.). 
sko prenašanje jezika, število in heterogenost funkcij, ki jih opravlja, nadalje konstelacija jezikov, s katerimi prihaja v stik oz. s katerimi tekmuje itd.

Toda vloga angleščine v Evropi je danes drugačna: angleščina ima tukaj predvsem status sredstva za mednarodno sporazumevanje in večinoma $s$ posameznimi nacionalnimi jeziki ne tekmuje za prevzem njihovih vlog $\mathrm{v}$ domači komunikaciji, razen $\mathrm{v}$ nekaterih državah na določenih področjih rabe, npr. kot jezik znanosti. Znan je primer Nizozemske, kjer je bil zaradi želje po odpiranju v svet in po interakciji s kar najširšim krogom študentov in raziskovalcev na univerzah že pred časom uveden pouk $\mathrm{v}$ angleščini na škodo nizozemščine. Poznavanje takšnih izkušenj je na vsak način lahko v pomoč pri jezikovnem načrtovanju $\mathrm{v}$ drugih državah ali celo minimalno varovalo pred prenagljenimi odločitvami, vendar nikakor ne moremo na njihovi osnovi posploševati in trditi, da angleščina kot jezik mednarodnega sporazumevanja pomeni nevarnost za druge jezike.

\section{Evropska večjezičnost in (zunaj)jezikovne hierarhije}

Skratka, prihodnost Evrope je v ohranjanju in razvijanju večjezičnosti; najprej v skrbi za nacionalne jezike in za materinščine evropskih govorcev nasploh, nato pa v čim kvalitetnejšem usvajanju tujih jezikov, od katerih naj bi bil eden jezik mednarodne komunikacije. Dvo- ali večjezičnost dejansko ni nič novega, v Evropi imamo nekaj držav, kjer je dvo- ali večjezičnost običajna in dobro funkcionira, kot recimo v Švici. Novo je zdaj morda predvsem to, da je dvo- ali večjezičnost pojmovana kot vrednota in da jo ima za enega izobraževalnih ciljev velika večina evropskih držav in seveda tudi Evropska unija, in sicer na ravni najširše populacije, na poseben način pa na dvojezičnih ali večjezičnih območjih, čeprav je tovrstna, pogosto vsaj do neke mere spontana dvojezičnost seveda lahko zelo drugačna od dvojezičnosti, kakršna se razvije, ko usvajanje jezika ne poteka iz naravnega okolja (prim. Lo Cascio, 2006, 77). Skoz zgodovino je bila vsaj v Evropi dvo- ali večjezičnost v mnogih okoljih običajnejša od enojezičnosti, izrazito tudi na Slovenskem (cfr. Prunč, 1997; Stabej, 1998, 22-23), čeprav se je raven znanja posameznih jezikov po obdobjih zelo razlikovala in je bila pogojena 
tudi socialno; večinoma je šlo prej kot za dvojezičnost v pravem pomenu besede za diglosijo, se pravi za situacijo, v kateri so jezikovne funkcije med jezikoma oz. jeziki porazdeljene, npr. tako, da se eden uporablja večinoma za pisno sporočanje, drugi pa večinoma za ustno sporočanje, ali pa tako, da se eden uporablja bolj v neformalnih okoliščinah (npr. pri komunikaciji $\mathrm{z}$ družino in prijatelji), drugi pa bolj v formalnih okoliščinah (npr. v šoli, službi itd.).

Pričevanja o večjezičnosti v Evropi so nadvse bogata. Zaradi medetničnih izmenjav je namreč nenehno prihajalo tudi do jezikovnih stikov, in sicer vse od začetka zgodovine, o čemer navsezadnje priča tudi starost prevajalskega oz. tolmaškega poklica. Če se zopet pomudimo ob latinščini, lahko ugotovimo, da so v antičnih virih izpričani njeni živahni stiki z mnogimi jeziki, z etruščino, punščino, hebrejščino, gotščino. Posebej močni so bili stiki z grščino, kot je razvidno iz besedil najrazličnejših, tudi klasičnih avtorjev, kot je Cicero, v katerega pismih pa tudi drugih besedilih najdemo obilo grškega gradiva (prim. Swain, 2002). Grščina je bila v starem Rimu močno prisotna in se je na široko poučevala $\mathrm{v}$ šolah; o intenzivnosti stikov med jezikoma priča tudi raznolikost kontaktnih fenomenov, med katerimi so izposojenke, skladenjske in druge interference, primeri preklapljanja in mešanja koda itd., in to $v$ književnih in neknjiževnih besedilih, predvsem $\mathrm{v}$ slednjih pogosto zaradi prevzemanja terminologije iz grščine (prim. Biville, 2002, 86 passim). Podobne pojave bi lahko ugotavljali za verjetno vse ostale evropske jezike v odnosu do drugih jezikov, s katerimi so (bili) v stiku.

Toda jeziki v stiku stopajo med seboj vselej tudi v razmerja moči. Kot smo videli, so v primerjavi $z$ angleščino na področju mednarodne komunikacije vsi v šibkejšem položaju, toda pri evropskih jezikih, ki jih angleščina načeloma ne ogroža, bolj kot prevlada angleščine mnoge jezike pesti moč jezikov, s katerimi se neposredno srečujejo. Najbolj zaščiteni so jeziki, ki imajo status državnega jezika, saj jim politična institucija, ki jih uporablja in ponavadi tudi omogoča njihovo rabo v karseda raznolikih situacijah, podeljuje moč, kakršne sicer ne bi mogli imeti. A čeprav je vprašanje jezika tudi politikum, se to, da ima dani jezik status državnega jezika v ustavah le redko omenja, to pa najbrž zato, ker se vloga jezika, za katerim stoji državna institucija, zdi sama po sebi umevna. V slovenski ustavi je uradnost slovenščine omenjena, in to najbrž lahko »interpretiramo tudi kot posle- 
dico bojazni načrtovalcev, da bi bil sicer tak status ogrožen oziroma celo neuresničen « (Stabej, 2003, 58). A mnogi jeziki v Evropi nimajo takšne sreče, čeprav je seveda res, da so medjezikovna razmerja moči spremenljiva in da navidez trdno določena usoda lahko ubere tudi drugačno pot, ponavadi v neposredni odvisnosti od političnih okoliščin. Skoz čas je bila Evropa pri jezikovni politiki pogosto vse prej kot demokratična; primerov prepovedi rabe jezika, bodisi v celoti bodisi delno (npr. v javnosti, vključno $\mathrm{z}$ rabo $\mathrm{v}$ šoli), in sankcij ob njenem neupoštevanju je veliko: znana je npr. Francija, ki je bila s svojimi regionalnimi jeziki (okcitanščino, bretonščino, korzijščino itd.) posebej ostra, na Slovenskem pa se iz ne tako daljne preteklosti spomnimo fašistične jezikovne politike na Primorskem. Večkrat so posamezne države načrtno naseljevale novo prebivalstvo na območja, ki so jih želele jezikovno spremeniti, npr. Francija na nekaterih območjih Alzacije, Italija pa v dolini Aoste (Iannàccaro/Dell'Aquila, 2004, 122, 128) in tudi na Tržaškem. Toda ukrepi represivne jezikovne politike so, vsaj pri zgodbah s srečnim koncem, začasni. Ena takih zgodb je med drugim katalonska: jezik, ki je bil v času frankizma prepovedan, je danes v razcvetu in v Kataloniji španščino oz. kastiljščino čedalje bolj postavlja v položaj drugega jezika. Tudi baskovski primer priča o tem, kako s pridobivanjem politične avtonomije etnična skupnost lahko ustvarja ugodne okoliščine za rabo in razvoj svojega jezika, in obenem ponazarja, kako različni sta si lahko instrumentalna in simbolna funkcija jezika: številni člani baskovske skupnosti jezika sploh niso obvladali, a so se vseeno počutili Baske, nato pa se je začelo postopno uvajanje baskovščine v šolo, kjer je ta sprva v glavnem kot šolski predmet sobivala ob močni španščini, a je za mnoge učence sčasoma postala jezik poučevanja (Iannàccaro/Dell'Acquila, 2004, 123-124). Podobno tudi Irci ne občutijo nujno znanja irščine kot poglavitno obeležje irskosti (Crowley, 2005, 186-187), čeprav tudi irščina oživlja, in sicer ravno zato, ker ima kljub za številne Irce nizkemu instrumentalnemu potencialu veliko simbolno vrednost kot znak nacionalne pripadnosti, pogosto skupaj s katolištvom. Tovrstnih situacij je še veliko; navsezadnje imajo tudi mnogi potomci slovenskih izseljencev do slovenščine podoben odnos.

Kako politično je vprašanje o jeziku in kako tesno sta včasih sprepleteni instrumentalna in simbolna vloga jezika, naj za konec ponazori tale primer: na lističu, ki vabi k vpisu na jezikovne tečaje okcitanščine v Toulousu, 
so poleg praktičnih informacij v okvirju natisnjene tudi besede Frédérica Mistrala:

"Qu'un pòble tombe esclau

Se tèn sa lenga tèn la clau

Que dei cadenas lo deslieura«

v dobesednem prevodu: »Ko narod postane suženj, / če ima svoj jezik, ima ključ, / ki ga bo odrešil spon«; in v zasilnem manj dobesednem: »Ko narod izgubi prostost, / če ima jezik, ima most, / ki ga bo iz suženjstva popeljal«.

Da ima Mistral prav, priča zgodovina številnih evropskih narodov in hkrati zgodovina mnogih evropskih jezikov, morda tudi tista, ki je zaenkrat še prihodnost.

\section{BIBLIOGRAFIJA}

Baldi, Ph., The Foundations of Latin, Berlin 2002.

Biville, F., The Graeco-Romans and Graeco-Latin: Terminological Framework for Cases of Bilingualism, v: Bilingualism in Ancient Society: Language Contact and the Written Word (ur. Adams, J. N. idr.), Oxford 2002, str. 77-102.

Brezigar, B., Knjige v samokolnici, Trst 1999.

Calvet, L.-J., La guerre des langues et les politiques linguistiques, Paris 1999.

Carli, A., Alcuni criteri funzionali nella determinazione del potere di una lingua, v: Amant alterna Camenae: Studi linguistici offerti a Andrea Csillaghy in occasione del suo $60^{\circ}$ compleanno (ur. Carli, A. idr.), Alessandria 2000, str. 13-24. 
Crowley, T., Wars of Words: The Politics of Language in Ireland 1537-2004, Oxford 2005.

Crystal, D., English as a Global Language, Cambridge 1998.

Dell'Aquila, V./G. Iannàccaro, La pianificazione linguistica, Roma 2004.

Glinert, L., Hebrew, v: Encyclopedia of the Languages of Europe (ur. Price, G.), Oxford 1998, str. 225-228.

Lo Cascio, V., Lingue di cultura e lingue internazionali nell'Europa unita, v: Fare gli Europei./Ustvariti Evropejce (ur. Košuta, M.), Trst 2006, str. $69-78$.

Nettle, D./S. Romaine, Vanishing Voices: The Extinction of World's Languages, Oxford 2000.

Ostler, N., Ad Infinitum: A Biography of Latin, New York, 2007.

Prunč, E., Slovenščina in jezikovna enakopravnost v mednarodni komunikaciji, Slavistična revija 45/3-4, 1997, str. 547-557.

Stabej, M., Oblikovanje knjižnega jezika v 19. stoletju med narodno enotnostjo in socialno razločevalnostjo, v: XXXIV. seminar slovenskega jezika, literature in kulture (ur. Kržišnik, E.), Ljubljana 1998, str. 19-33.

Stabej, M., Bo en jezik dovolj? Večjezičnost v enojezičnosti, v: Slovenski knjižni jezik - aktualna vprašanja in zgodovinske izkušnje: Mednarodni simpozij Obdobja (ur. Vidovič Muha, A.), Ljubljana 2003, str. 51-70.

Swain, S., Bilingualism in Cicero? The Evidence of Code-Switching, v: Bilingualism in Ancient Society: Language Contact and the Written Word (ur. Adams, J. N. idr.), Oxford 2002, str. 128-167.

Waquet, F., Latin or the Empire of a Sign, prev. John Howe, London 2001. 


\section{EUROPEAN LANGUAGES: INSTRUMENTS AND SYMBOLS}

Keywords: European languages, role of Latin, lingua franca, national languages, language endangerment, language planning

\section{Abstract}

The authors attempt to give an overview of some general external features of European languages today, defining the language families and languages which qualify for inclusion in this group and specifying the following features as characteristic of the European linguistic situation: relative stability since the early Middle Ages, given that there has been no considerable influx of new languages which would have radically altered the typological language map; a relatively low degree of typological heterogeneity; a relatively high degree of documentation; spread of various »European languages « to other continents. Indeed the term »European languages« is somewhat problematic in that, from both contemporary and historical perspective, these languages are only partially justified to be considered as such. It is proposed that the concept of »European languages « should be kept distinct from the related concept of »languages used/spoken in Europe«.

Further, the role of Latin as the single most important European language over the centuries and as a unifying feature of European culture is discussed. Parallels are drawn between Latin as the historical European lingua franca on the one hand and English as the modern language of international communication on the other: the importance of both languages started growing after substantial territorial expansion of their speakers and it was especially the political and economic power associated to these languages that played a significant role in their diffusion and long-term influence. Taking into consideration the instrumental as well as the symbolic function of languages, the question about the relationship between English and other European languages in today's Europe is dealt with; it is suggested that the European languages are in principle not endangered as a result of the spread of English, with the exception of those instances in 
which English has been taking over the functions they have traditionally performed as national or community languages. It is emphasized that the future of Europe lies in the promotion of bi- and multilingualism, which have, in actual fact, been present on this continent throughout its history, and which in the cases of some European languages (e.g. Catalan, Basque, Irish, etc.) have been successfully enhanced over the past decades. 